\title{
Nutrition in Colombian pregnant women
}

\author{
Olga L Sarmiento ${ }^{1, *}$, Andrea Ramirez', Belén Samper Kutschbach², Paula L Pinzón ${ }^{1}$, \\ Sandra García ${ }^{3}$, Angie C Olarte ${ }^{1}$, Tatiana Mosquera ${ }^{1}$, Eduardo Atalah ${ }^{4}$, \\ Gabriel Ojeda ${ }^{3}$ and Yibby Forero ${ }^{5}$ \\ 'Department of Public Health, School of Medicine, Universidad de los Andes, Carrera $1^{a}$ \# 18A-10, Bogotá, \\ Colombia: ${ }^{2}$ Profamilia, Department of Research and Evaluation, Bogotá, Colombia: ${ }^{3}$ School of Government, \\ Universidad de los Andes, Bogotá, Colombia: ${ }^{4}$ Department of Nutrition, Faculty of Medicine, Universidad de \\ Chile, Santiago, Chile: ${ }^{5}$ National Institute of Health (Instituto Nacional de Salud), Bogotá, Colombia
}

Submitted 5 March 2011: Accepted 17 November 2011: First published online 5 January 2012

\begin{abstract}
Objective: The present study aimed to evaluate the nutritional status of pregnant women in Colombia and the associations between gestational BMI and sociodemographic and gestational characteristics.

Design: Cross-sectional study. A secondary analysis was made of data from the 2005 Demographic and Health Survey of Colombia.

Setting: Bogotá, Colombia.

Subjects: Pregnant adolescents aged $13-19$ years $(n$ 430) and pregnant women aged 20-49 years ( $n$ 1272).

Results: The gestational BMI and sociodemographic characteristics of the adolescents differed from those of the pregnant adult women. Thirty-one per cent of the adolescents were underweight for gestational age, compared with $14.5 \%$ of the adult women. Eighteen per cent of adolescents were overweight for gestational age, in contrast to $37 \cdot 3 \%$ of adult women. The overall prevalence of anaemia was $44 \cdot 7 \%$ and the prevalence of low serum ferritin was $38 \cdot 8 \%$. Women within the high quintiles of the wealth index (prevalence odds ratio (POR) $=0 \cdot 56$; $95 \%$ CI $0 \cdot 34,0 \cdot 91, P<0 \cdot 02$ ) had lower odds of being underweight. Women who received prenatal care $(\mathrm{POR}=2 \cdot 17 ; 95 \% \mathrm{CI} 1 \cdot 48,3 \cdot 09, P<0 \cdot 001)$ and were multiparous $(\mathrm{POR}=2 \cdot 10 ; 95 \%$ CI $1 \cdot 43,3 \cdot 15, P<0 \cdot 001)$ had higher odds of being overweight. Women in extended families ( $\mathrm{POR}=0 \cdot 63 ; 95 \% \mathrm{CI} 0 \cdot 50,0 \cdot 95$, $P<0 \cdot 025)$ had lower odds of being overweight.

Conclusions: Underweight in pregnant adolescents and overweight in adult women coexist as a double burden in Colombia. Factors associated with malnutrition among pregnant women and adolescents should be considered for future interventions in countries experiencing nutritional transition.
\end{abstract}

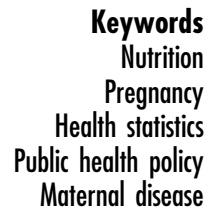

Nutrition

Pregnancy (1) Maternal disease
Currently, the double burden and nutritional paradox of simultaneous underweight and overweight is present throughout the developing world and mostly affects women $^{(1,2)}$. Likewise, the phenomenon of nutritional transition, which refers to the shifting burden of obesity from socio-economically privileged groups to the poor, has been observed over recent decades in several low- and middle-income countries, particularly among women ${ }^{(1,3,4)}$.

Nutritional status among pregnant women is known to be a determinant of health for both the women and their newborns ${ }^{(5)}$. Worldwide, the prevalence of maternal undernutrition ranges from $10 \%$ to $19 \%$, being more common among poor populations ${ }^{(6)}$.

Undernutrition in pregnancy is associated with an increased risk of maternal and infant morbidity and mortality.
Short-term consequences of undernutrition include intrauterine growth restriction, small-for-gestational-age infants, preterm labour and perinatal death ${ }^{(5,7)}$. Long-term consequences include stunting among children, which leads to shorter adult height, lower intellectual ability, reduced adult income and increased risk of chronic diseases such as hypertension, coronary disease, insulin resistance, diabetes mellitus and hyperlipidaemia ${ }^{(7-10)}$.

In addition, pregnant women are at risk of multiple micronutrient deficiencies, including deficiencies of $\mathrm{Fe}$, folic acid, riboflavin and vitamins $\mathrm{A}, \mathrm{D}, \mathrm{B}_{6}$ and $\mathrm{B}_{12}{ }^{\left({ }^{(9)}\right.}$. Fe deficiency is the most prevalent and neglected nutrient deficiency in the world, affecting 30\% of the world's population and 56 million pregnant women ${ }^{(11,12)}$. In developing countries, inadequate intake of $\mathrm{Fe}$ coupled 
with increased requirements during pregnancy exacerbate maternal deficiency and potentiate adverse effects for the mother and the child ${ }^{(12)}$.

The prevalence of overweight and obesity during pregnancy has been increasing rapidly in both developed and developing countries, affecting women of all ages ${ }^{(13-16)}$. In the USA the prevalence ranges between $10 \%$ and $39 \%(17,18)$. In Latin America, Brazil reports a prevalence of $22 \%^{(19)}$, and in some African countries obesity is as high as $14 \%^{(20,21)}$.

Short-term consequences of obesity during pregnancy include spontaneous abortion, recurrent miscarriage, congenital anomalies like neural tube and cardiac defects, pre-eclampsia, gestational diabetes, preterm birth and stillbirth $^{(22)}$. The risk of gestational diabetes mellitus increases twofold for overweight women and eightfold for obese women ${ }^{(23,24)}$. In the peripartum period, there is an increased prevalence of Caesarean section, induced labour, receiving oxytocin, slower progression through labour and complications of Caesarean section such as wound infection and excessive blood loss.

The long-term consequences include retaining weight gain after pregnancy, maternal progression to type 2 diabetes, childhood obesity and, later in life, higher blood pressure and type 2 diabetes ${ }^{(23,25,26)}$. Infants born to overweight and obese women are more likely to suffer fetal macrosomia and shoulder dystocia ${ }^{(22,23,26,27)}$.

There is growing recognition among clinicians and public health workers that the approaches used to prevent and respond to health problems among pregnant women need to account for the different health problems within adults and adolescents ${ }^{(7,28)}$. Importantly, adolescent pregnancy in developing countries has been associated with poor nutrition and an increased severity of micronutrient deficiencies $^{(28)}$

In recent decades, adolescent pregnancy has become an important health issue in developing countries. The adolescent fertility rate in developed countries was 29 births per 1000 women, while in developing countries it was 133 births per 1000 women. In Colombia, the adolescent fertility rate increased significantly from 70 per 1000 in 1990 to 90 per 1000 in $2005^{(28)}$.

For these reasons, it is necessary to assess the nutritional status of the pregnant population, while accounting for differences between adolescents and adults. Therefore, the present analysis aimed to estimate the prevalence of underweight and overweight among pregnant adolescents and pregnant adult women, and to assess the associations between gestational BMI and sociodemographic and pregnancy factors ${ }^{(28)}$.

Colombia is a unique setting in which to explore malnutrition in pregnant women and adolescents, because the prevalence of both underweight and overweight is relatively high and the nutritional transition is apparent from the fact that the obesity gradient has already tipped against women in the poorest households. The findings of our analysis could thus guide future interventions and public health policies for pregnant women in developing countries experiencing nutritional transition.

\section{Experimental methods}

\section{Setting}

In 2005, Colombia had an estimated population of almost 43 million. Approximately half were females, 19\% were between 10 and 19 years of age and $43 \%$ were between 20 and 49 years of age. About $17 \%$ of the population lived on less than \$US 2 per day and $7 \%$ on less than \$US 1 per day, $89.9 \%$ knew how to read and write, $37 \cdot 2 \%$ had finished elementary school and $31.7 \%$ had completed high school ${ }^{(29,30)}$.

\section{Sampling design and study population}

We conducted a secondary analysis of cross-sectional data from the 2005 Demographic and Health Survey of Colombia (Encuesta Nacional de Demografía y Salud (ENDS)) and the National Nutritional Survey (Encuesta Nacional de la Situación Nutricional en Colombia $($ ENSIN $))^{(28)}$. The Demographic and Health Surveys are conducted in seventy-five countries worldwide as part of a project by the US Agency for International Development (coordinated by ICF Macro International) ${ }^{(31)}$.

ENDS applied a multistage, stratified, population-based cluster sampling design to a national sample of 37211 households stratified by cluster (household segments) that included 41344 women of reproductive age (13-49 years old). From this sample $1702(4 \cdot 1 \%)$ were pregnant at the time of interview. The survey obtained complete anthropometric information for 1620 women, the sample for the present analysis.

The original questionnaire contained both household and individual components and was administered with computer-assisted personal interview technology. All protocols were approved by the Profamilia Institutional Review Board on Research Involving Human Subjects.

\section{Outcome measurement}

The maternal weight and height used to calculate BMI were measured by trained personnel with calibrated equipment. The outcome BMI for gestational age was calculated using the algorithm developed by Atalah et al $^{(32,33)}$. The algorithm was based on a reference table of BMI from the 10th to the 42nd week of gestation. The FAO/WHO BMI classification for non-pregnant women was used for the first 10 weeks of gestation and contained the following categories: underweight $\left(\mathrm{BMI}<18 \cdot 50 \mathrm{~kg} / \mathrm{m}^{2}\right)$, normal weight $(\mathrm{BMI}=18 \cdot 50$ $\left.24.99 \mathrm{~kg} / \mathrm{m}^{2}\right)$, overweight $\left(\mathrm{BMI}=25 \cdot 00-29 \cdot 99 \mathrm{~kg} / \mathrm{m}^{2}\right)$ and obese $\left(\mathrm{BMI} \geq 30 \cdot 00 \mathrm{~kg} / \mathrm{m}^{2}\right)^{(34)}$. According to data from Thomson and Billewicz, the average cumulative weight gain in the first 10 weeks of gestation is $600 \mathrm{~g}$, equivalent to $0.25 \mathrm{~kg} / \mathrm{m}^{2}$ for women of $1.55 \mathrm{~m}^{(35)}$. The 'ideal' increase in 
weight for women with normal BMI is estimated to be $20 \%$ of the pre-pregnancy weight, which is associated with lower maternal and fetal morbidity and mortality in most studies ${ }^{(17-19,21,23,36-38)}$. This is equivalent to $11 \mathrm{~kg}$ for a woman with a height of $1.55 \mathrm{~m}$ and a BMI of $23.0 \mathrm{~kg} / \mathrm{m}^{2}$ (about $4.5 \mathrm{~kg} / \mathrm{m}^{2}$ ). The slope of the curve along the pregnancy is assumed to have a sigmoid shape, with the greatest increase between the 20th and 30th weeks ${ }^{(35,36,38)}$, and it should be higher in emaciated women and lower in pregnant women with overweight and obesity. This algorithm was validated in 1997 with a cohort of 665 pregnant women in six selected clinics in Chile ${ }^{(32)}$. The algorithm has been used in at least four nutritional surveys in Latin American countries ${ }^{(32,39-44)}$.

\section{Measures of independent variables}

The sociodemographic characteristics included age (adolescents aged 13-19 years $v$. adults aged 20-49 years), education (no formal education or elementary school $v$. high school or higher education), wealth index (WI; 1st and 2nd quintiles $v$. 3rd quintile $v$. 4th and 5th quintiles), family structure (single person or nuclear family $v$. extended family), marital status (single $v$. married or member of an unmarried couple) and urbanicity (urban $v$. rural). The age cut-off point for adolescence was determined according to WHO recommendations ${ }^{(45)}$. The WI was developed by the World Bank for world populations, as a measure of wealth distribution across a country, taking into account respondents' household assets, amenities and services $^{(31)}$.

The pregnancy-related characteristics included health insurance status (no $v$. yes), prenatal care during pregnancy (no $v$. yes), trimester of pregnancy and parity (nulliparous $v$. multiparous).

$\mathrm{Hb}$ and serum ferritin (SF) concentrations were also measured in subsamples of 667 and 571 pregnant women. $\mathrm{Hb}$ was measured by the Hemocue method and adjusted by altitude as recommended by the International Nutritional Anemia Consultative Group ${ }^{(46)}$. Anaemia was defined as having $\mathrm{Hb}<11 \mathrm{~g} / \mathrm{dl}$. SF was determined by chemiluminescence, using an automatic analyser (ADIVIA Centaur ${ }^{\circledR}$ ). Low SF level was used as an indicator of Fe deficiency and the cut-off for depleted Fe stores was defined as SF $<12 \mu \mathrm{g} / \mathrm{l}^{(11,47,48)}$. Our analysis excludes women with levels of C-reactive protein above $1.2 \mathrm{mg} / \mathrm{dl}^{(11,47,48)}$.

\section{Statistical methods}

Our analytic strategy involved several steps. First, we described the nutritional status of pregnant women based on the gestational BMI (underweight $v$. normal weight $v$. overweight). Second, we conducted bivariate and multivariate analyses using unordered multinomial logistic regression models to assess the association between independent variables with the categories of gestational BMI, with the normal category as the reference.
Collinearity between independent variables was evaluated using regression diagnostic tests. All analyses were conducted using the statistical software packages SAS version 9.1 (SAS Institute Inc., Cary, NC, USA) and STATA version $9 \cdot 0$ (StataCorp LP, College Station, TX, USA) with appropriate weighting and adjustment for the sampling design.

\section{Results}

\section{Study population}

Of all the pregnant women sampled, $24 \cdot 7 \%$ were adolescents, with an average age of $17 \cdot 16$ (SD $1 \cdot 45$ ) years, and $75 \cdot 3 \%$ were adults, with an average age of $27 \cdot 39$ (SD 5.47) years. Sixty-eight per cent of all the pregnant women reported having attended school beyond the elementary level, $47 \cdot 3 \%$ were in the first and second WI quintiles and $50.7 \%$ had extended families. Most women were married or a member of an unmarried couple $(73 \cdot 6 \%)$, lived in urban areas $(69 \cdot 8 \%)$, reported having health insurance $(65 \cdot 3 \%)$ and reported receiving prenatal care during pregnancy $(75 \cdot 7 \%)$. Forty-one per cent were in their second trimester of pregnancy, and $60.5 \%$ were multiparous (Table 1 )

Pregnant adolescents differed significantly from pregnant adult women in certain sociodemographic and pregnancy characteristics (Table 2). Adolescents were more likely to live in extended families and to be nulliparous. Although not statistically significant, $53 \cdot 1 \%$ of adolescents were in the first and second WI quintiles and $22.5 \%$ were multiparous. In contrast, adult women were more likely to be married or a member of an unmarried couple, to have health insurance and to report receiving prenatal care during pregnancy.

\section{Prevalence of underweight and overweight among pregnant women}

Overall, $18.6(95 \%$ CI $16 \cdot 1,21 \cdot 4) \%$ of all pregnant women were underweight, $48 \cdot 8(95 \%$ CI $45 \cdot 3,52 \cdot 3) \%$ were of normal weight and $32 \cdot 6$ (95\% CI $29 \cdot 0,36 \cdot 3) \%$ were overweight. Among the subsamples of pregnant women with $\mathrm{Hb}$ and $\mathrm{SF}$ measurements, the mean $\mathrm{Hb}$ level was $11 \mathrm{~g} / \mathrm{dl}$ and the mean SF level was $24 \mu \mathrm{g} / \mathrm{l}$. Almost half of the women had anaemia, and $38.8 \%$ had depleted Fe stores (Table 1).

The adolescents and the adult women differed in their gestational BMI: while $31 \cdot 2 \%$ of the adolescents were underweight, $14.5 \%$ of the adult women were underweight. In contrast, $18.0 \%$ of the adolescents were overweight compared with $37 \cdot 3 \%$ of the adult women (Fig. 1, Table 2). Although both the adolescents and the adult women showed a high prevalence of anaemia and Fe store deficiency, the adolescents exhibited a pattern of higher deficiencies, though not one that was statistically significant (Table 2). 
Table 1 Sociodemographic and pregnancy characteristics among pregnant women in Colombia, Demographic and Health Survey (ENDS) and National Nutritional Survey (ENSIN), 2005

\begin{tabular}{|c|c|c|c|}
\hline Variable & $n^{*}$ & Weighted \% & $95 \% \mathrm{Cl}$ \\
\hline \multicolumn{4}{|l|}{ Sociodemographic characteristics } \\
\hline \multicolumn{4}{|l|}{ Age } \\
\hline Adolescence, $13-19$ years & 430 & $24 \cdot 7$ & $21 \cdot 9,27 \cdot 8$ \\
\hline Adult, $20-49$ years & 1272 & $75 \cdot 3$ & $72 \cdot 2,78 \cdot 1$ \\
\hline \multicolumn{4}{|l|}{ Education } \\
\hline No formal education or elementary school & 562 & $32 \cdot 3$ & $29 \cdot 0,35 \cdot 7$ \\
\hline High school or higher education & 1140 & $67 \cdot 7$ & $64 \cdot 3,71 \cdot 0$ \\
\hline \multicolumn{4}{|l|}{ Wealth index } \\
\hline 1st and 2nd quintiles (lowest-low) & 922 & $47 \cdot 3$ & $43 \cdot 3,51 \cdot 4$ \\
\hline 3rd quintile (medium) & 406 & $22 \cdot 6$ & $19 \cdot 8,25 \cdot 6$ \\
\hline 4th and 5th quintiles (high-highest) & 374 & $30 \cdot 1$ & $26 \cdot 5,34 \cdot 0$ \\
\hline \multicolumn{4}{|l|}{ Family structure } \\
\hline Single person or nuclear family & 849 & $49 \cdot 3$ & $45 \cdot 9,52 \cdot 7$ \\
\hline Extended family & 853 & $50 \cdot 7$ & $47 \cdot 3,54 \cdot 1$ \\
\hline \multicolumn{4}{|l|}{ Marital status } \\
\hline Single & 450 & $26 \cdot 4$ & $23 \cdot 5,29 \cdot 5$ \\
\hline Married or member of an unmarried couple & 1252 & $73 \cdot 6$ & $70 \cdot 5,76 \cdot 5$ \\
\hline \multicolumn{4}{|l|}{ Urbanicity } \\
\hline Urban & 1221 & $69 \cdot 8$ & $65 \cdot 4,73 \cdot 8$ \\
\hline Rural & 481 & $30 \cdot 2$ & $26 \cdot 2,34 \cdot 6$ \\
\hline \multicolumn{4}{|l|}{ Pregnancy characteristics } \\
\hline \multicolumn{4}{|l|}{ Health insurance } \\
\hline No & 587 & $34 \cdot 7$ & $31 \cdot 4,38 \cdot 1$ \\
\hline Yes & 1108 & $65 \cdot 3$ & $61 \cdot 9,68 \cdot 6$ \\
\hline \multicolumn{4}{|l|}{ Prenatal care during pregnancy } \\
\hline No & 428 & $24 \cdot 3$ & $21 \cdot 5,21 \cdot 2$ \\
\hline Yes & 1274 & $75 \cdot 7$ & $72 \cdot 9,78 \cdot 5$ \\
\hline \multicolumn{4}{|l|}{ Trimester of pregnancy } \\
\hline 1st & 505 & $29 \cdot 9$ & $27 \cdot 0,32 \cdot 8$ \\
\hline 2nd & 696 & $41 \cdot 5$ & $38 \cdot 2,44 \cdot 9$ \\
\hline 3 rd & 501 & $28 \cdot 6$ & $25 \cdot 4,31 \cdot 7$ \\
\hline \multicolumn{4}{|l|}{ Parity } \\
\hline Nulliparous & 688 & $39 \cdot 6$ & $36 \cdot 2,42 \cdot 9$ \\
\hline Multiparous & 1014 & $60 \cdot 5$ & $57 \cdot 1,63 \cdot 8$ \\
\hline \multicolumn{4}{|l|}{ Nutritional status by gestational BMI } \\
\hline Underweight & 307 & $18 \cdot 6$ & $16 \cdot 1,21 \cdot 4$ \\
\hline Normal weight & 776 & $48 \cdot 8$ & $45 \cdot 3,52 \cdot 3$ \\
\hline Overweight/obese & 537 & $32 \cdot 6$ & $29 \cdot 0,36 \cdot 3$ \\
\hline \multicolumn{4}{|l|}{ Anaemia } \\
\hline $\mathrm{Hb}<11 \mathrm{~g} / \mathrm{dl}$ & 667 & $44 \cdot 7$ & $40 \cdot 8,48 \cdot 6$ \\
\hline $\mathrm{SF}<12 \mu \mathrm{g} / \mathrm{l}$ & 571 & $38 \cdot 8$ & $34 \cdot 8,43 \cdot 0$ \\
\hline
\end{tabular}

SF, serum ferritin.

*Unweighted sample size. Sample sizes may not sum to total $N$ due to missing data.

\section{Underweight-related factors}

In the bivariate analysis, adolescent pregnant women had higher odds of being underweight compared with adult pregnant women. Women in the highest WI quintiles, who had health insurance and were multiparous had lower odds of being underweight compared with their comparison groups (Table 3).

In the multivariate analysis, the associations between underweight and being an adolescent and being in the WI highest quintile remained statistically significant (Table 4).

\section{Overweight-related factors}

In the bivariate analysis, adolescent pregnant women had lower odds of being overweight compared with adult pregnant women. Women who attended prenatal care, were multiparous and were in the third trimester of pregnancy had higher odds of being overweight than their comparison groups. In contrast, pregnant women living in extended families had lower odds of being overweight compared with pregnant women living in nuclear families (Table 3).

In the multivariate analysis, associations between overweight and being an adolescent, living in an extended family, reporting prenatal care during pregnancy and multiparity remained statistically significant (Table 4).

\section{Discussion}

Our findings provide evidence of the double burden within the pregnant population. Adolescents were more likely to be underweight and adults were more likely to be overweight. Overall, our results indicate that only about half of all pregnant women in Colombia had normal gestational BMI. Low gestational BMI was present 
Table 2 Sociodemographic and pregnancy characteristics of pregnant adolescents and adult women in Colombia, Demographic and Health Survey (ENDS) and National Nutritional Survey (ENSIN), 2005

\begin{tabular}{|c|c|c|c|c|c|}
\hline \multirow[b]{2}{*}{ Variable } & \multicolumn{2}{|c|}{ Adolescents ( $n$ 430) } & \multicolumn{2}{|c|}{ Adults ( $n$ 1272) } & \multirow[b]{2}{*}{$P$ value } \\
\hline & Weighted \% & $95 \% \mathrm{Cl}$ & Weighted \% & $95 \% \mathrm{Cl}$ & \\
\hline \multicolumn{6}{|l|}{ Sociodemographic characteristics } \\
\hline \multicolumn{6}{|l|}{ Education } \\
\hline No formal education or elementary school & $29 \cdot 7$ & $23 \cdot 8,36 \cdot 4$ & $33 \cdot 1$ & $29 \cdot 4,37 \cdot 1$ & \multirow[t]{2}{*}{0.368} \\
\hline High school or higher education & $70 \cdot 3$ & $63 \cdot 6,76 \cdot 2$ & $66 \cdot 8$ & $62 \cdot 9,70 \cdot 6$ & \\
\hline \multicolumn{6}{|l|}{ Wealth index } \\
\hline 1st and 2nd quintiles & $53 \cdot 1$ & $45 \cdot 7,60 \cdot 4$ & $45 \cdot 4$ & $41 \cdot 0,49 \cdot 9$ & \multirow{3}{*}{$0 \cdot 218$} \\
\hline 3rd quintile & $20 \cdot 0$ & $15 \cdot 1,26 \cdot 1$ & $23 \cdot 3$ & $20 \cdot 2,26 \cdot 9$ & \\
\hline 4th and 5th quintiles & $26 \cdot 8$ & $20 \cdot 2,34 \cdot 9$ & $31 \cdot 2$ & $26 \cdot 9,35 \cdot 7$ & \\
\hline \multicolumn{6}{|l|}{ Family structure } \\
\hline Single person or nuclear family & $40 \cdot 8$ & $34 \cdot 8,47 \cdot 2$ & $52 \cdot 1$ & $48 \cdot 2,56 \cdot 0$ & \multirow{2}{*}{0.002} \\
\hline Extended family & $59 \cdot 1$ & $52 \cdot 8,65 \cdot 2$ & $47 \cdot 9$ & $44 \cdot 0,51 \cdot 8$ & \\
\hline \multicolumn{6}{|l|}{ Marital status } \\
\hline Single & $45 \cdot 0$ & $38 \cdot 5,51 \cdot 7$ & $20 \cdot 3$ & $17 \cdot 5,23 \cdot 3$ & \multirow[t]{2}{*}{$<0.001$} \\
\hline Married or member of an unmarried couple & $54 \cdot 9$ & $48 \cdot 3,61 \cdot 5$ & $79 \cdot 7$ & $76 \cdot 7,82 \cdot 5$ & \\
\hline \multicolumn{6}{|l|}{ Urbanicity } \\
\hline Urban & $68 \cdot 7$ & $61 \cdot 3,75 \cdot 4$ & $70 \cdot 1$ & $65 \cdot 5,74 \cdot 3$ & \multirow[t]{2}{*}{$0 \cdot 707$} \\
\hline Rural & $31 \cdot 2$ & $24 \cdot 6,38 \cdot 7$ & $29 \cdot 8$ & $25 \cdot 7,34 \cdot 5$ & \\
\hline \multicolumn{6}{|l|}{ Pregnancy characteristics } \\
\hline Health insurance & & & & & \multirow{3}{*}{0.0006} \\
\hline No & $44 \cdot 6$ & $37 \cdot 8,51 \cdot 7$ & $31 \cdot 4$ & $27 \cdot 9,35 \cdot 2$ & \\
\hline Yes & $55 \cdot 3$ & $48 \cdot 3,62 \cdot 2$ & $68 \cdot 6$ & $64 \cdot 8,72 \cdot 1$ & \\
\hline \multicolumn{6}{|l|}{ Prenatal care during pregnancy } \\
\hline No & $35 \cdot 8$ & $26 \cdot 8,38 \cdot 2$ & $20 \cdot 5$ & $17 \cdot 6,23 \cdot 5$ & \multirow[t]{2}{*}{$<0.001$} \\
\hline Yes & $64 \cdot 2$ & $57 \cdot 1,70 \cdot 7$ & $79 \cdot 5$ & $76 \cdot 5,82 \cdot 3$ & \\
\hline \multicolumn{6}{|l|}{ Parity } \\
\hline Nulliparous & $77 \cdot 5$ & $71 \cdot 1,82 \cdot 8$ & $27 \cdot 1$ & $23 \cdot 9,30 \cdot 6$ & \multirow[t]{2}{*}{$<0.001$} \\
\hline Multiparous & $22 \cdot 5$ & $17 \cdot 2,28 \cdot 9$ & $72 \cdot 9$ & $69 \cdot 4,76 \cdot 1$ & \\
\hline \multicolumn{6}{|l|}{ Trimester of pregnancy } \\
\hline $1 \mathrm{st}$ & $32 \cdot 4$ & $26 \cdot 8,38 \cdot 2$ & $29 \cdot 2$ & $26 \cdot 0,32 \cdot 6$ & \multirow[t]{3}{*}{0.368} \\
\hline 2nd & $37 \cdot 8$ & $31 \cdot 7,44 \cdot 3$ & $42 \cdot 8$ & $39 \cdot 0,46 \cdot 6$ & \\
\hline $3 r d$ & $30 \cdot 0$ & $24 \cdot 4,36 \cdot 3$ & $28 \cdot 1$ & $24 \cdot 8,31 \cdot 7$ & \\
\hline \multicolumn{6}{|l|}{ Nutritional status by gestational BMI } \\
\hline Underweight & $31 \cdot 2$ & $25 \cdot 4,37 \cdot 6$ & $14 \cdot 5$ & $12 \cdot 2,17 \cdot 2$ & \multirow[t]{3}{*}{$<0.001$} \\
\hline Normal weight & $50 \cdot 8$ & $43 \cdot 9,57 \cdot 6$ & $48 \cdot 1$ & $44 \cdot 2,52 \cdot 0$ & \\
\hline Overweight/obese & $18 \cdot 0$ & $0 \cdot 9,42 \cdot 0$ & $37 \cdot 3$ & $7 \cdot 4,12 \cdot 3$ & \\
\hline \multicolumn{6}{|l|}{ Anaemia } \\
\hline $\mathrm{Hb}<11 \mathrm{~g} / \mathrm{dl}$ & $51 \cdot 1$ & $42 \cdot 7,59 \cdot 4$ & $42 \cdot 9$ & $38 \cdot 6,47 \cdot 3$ & 0.089 \\
\hline $\mathrm{SF}<12 \mu \mathrm{g} / \mathrm{l}$ & $40 \cdot 6$ & $32 \cdot 0,49 \cdot 7$ & $38 \cdot 3$ & $33 \cdot 7,43 \cdot 0$ & 0.653 \\
\hline
\end{tabular}

SF, serum ferritin.

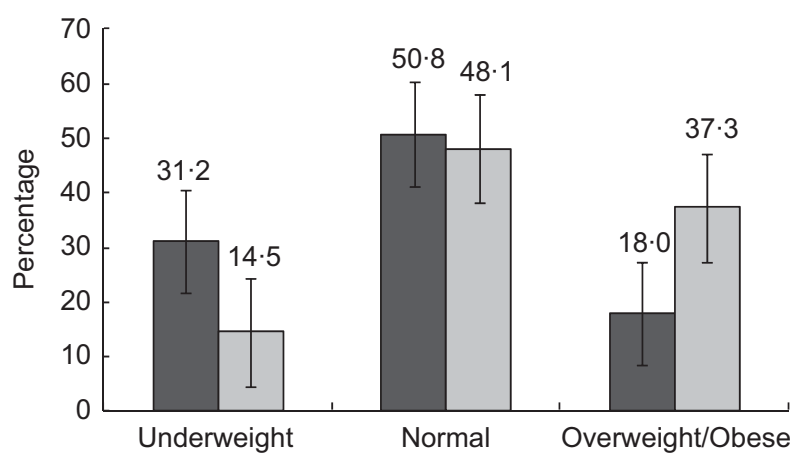

Fig. 1 Nutritional status by BMI among pregnant adolescents $(\square)$ and adult women $(\square)$ in Colombia, Demographic and Health Survey (ENDS) and National Nutritional Survey (ENSIN), 2005. Values are prevalence with $95 \%$ confidence intervals represented by vertical bars

in one-fifth of pregnant women, most of whom were adolescents. One-third of pregnant women, most of whom were adult women, were overweight.
In developing countries the nutritional transition and the double burden of nutrition are well recognized ${ }^{(1,3,49)}$. Among Latin American women there is evidence of an increase in the prevalence of overweight, which in many countries has exceeded $30 \%{ }^{(50)}$. This pattern of overweight coexists with a tendency to diminish the prevalence of underweight ${ }^{(50)}$. Our analysis of pregnant women provides, in part, evidence of this pattern. We found that the population in the lowest WI quintile had the highest prevalence of underweight, but that there were no differences in overweight by WI quintiles. In fact, among the pregnant population, in the lowest WI quintile $22 \%$ were underweight and $31 \%$ were overweight, while in the highest WI quintile $15 \%$ were underweight and $36 \%$ were overweight. In addition, we did not find the consistent differences seen in nutritional status between rural and urban population in other low- and middleincome countries ${ }^{(51)}$. This pattern could be the reflection of entering a later stage of nutritional transition, in which changes in diet and physical activity behaviours are 
Table 3 Bivariate associations between nutritional status and sociodemographic and pregnancy characteristics among pregnant women in Colombia, Demographic and Health Survey (ENDS) and National Nutritional Survey (ENSIN), 2005

\begin{tabular}{|c|c|c|c|c|c|c|c|c|}
\hline \multirow[b]{2}{*}{ Variable } & \multicolumn{4}{|c|}{ Underweight $v$. normal weight } & \multicolumn{4}{|c|}{ Overweight $v$. normal weight } \\
\hline & Weighted \% & POR & $95 \% \mathrm{Cl}$ & $P$ value & Weighted \% & POR & $95 \% \mathrm{Cl}$ & $P$ value \\
\hline \multicolumn{9}{|l|}{ Sociodemographic characteristics } \\
\hline \multicolumn{9}{|l|}{ Age } \\
\hline Adolescence, $13-19$ years & $31 \cdot 2$ & $2 \cdot 03$ & $1 \cdot 43,2 \cdot 89$ & $<0.001$ & $18 \cdot 0$ & 0.46 & $0.31,0.68$ & $<0.001$ \\
\hline Adult, $20-49$ years & $14 \cdot 5$ & $1 \cdot 00$ & Ref. & & $37 \cdot 3$ & $1 \cdot 00$ & Ref. & \\
\hline \multicolumn{9}{|l|}{ Education } \\
\hline No formal education or elementary school & $15 \cdot 4$ & $1 \cdot 00$ & Ref. & & $36 \cdot 1$ & $1 \cdot 00$ & Ref. & \\
\hline High school or higher education & $20 \cdot 2$ & $1 \cdot 30$ & $0.93,1 \cdot 83$ & $0 \cdot 129$ & $30 \cdot 9$ & $0 \cdot 85$ & $0 \cdot 62,1 \cdot 16$ & 0.293 \\
\hline \multicolumn{9}{|l|}{ Wealth index } \\
\hline 1st and 2nd quintiles & $21 \cdot 8$ & $1 \cdot 00$ & Ref. & & $31 \cdot 2$ & $1 \cdot 00$ & Ref. & \\
\hline 3rd quintile & $16 \cdot 5$ & 0.69 & $0 \cdot 46,1 \cdot 02$ & 0.064 & $31 \cdot 9$ & 0.93 & $0 \cdot 65,1 \cdot 34$ & 0.702 \\
\hline 4th and 5 th quintiles & $14 \cdot 6$ & 0.63 & $0.41,0.97$ & 0.035 & $35 \cdot 7$ & 1.08 & $0.71,1.64$ & $0 \cdot 710$ \\
\hline \multicolumn{9}{|l|}{ Family structure } \\
\hline Single person or nuclear family & $15 \cdot 6$ & $1 \cdot 00$ & Ref. & & $37 \cdot 7$ & 1.00 & Ref. & \\
\hline Extended family & $21 \cdot 5$ & $1 \cdot 26$ & $0 \cdot 89,1 \cdot 77$ & $0 \cdot 187$ & $27 \cdot 5$ & 0.67 & $0.49,0.92$ & 0.014 \\
\hline \multicolumn{9}{|l|}{ Marital status } \\
\hline Single & $20 \cdot 9$ & $1 \cdot 00$ & Ref. & & $27 \cdot 8$ & $1 \cdot 00$ & Ref. & \\
\hline Married or member of an unmarried couple & $17 \cdot 8$ & 0.92 & $0 \cdot 61,1 \cdot 37$ & 0.670 & $34 \cdot 3$ & $1 \cdot 33$ & $0.93,1 \cdot 88$ & $0 \cdot 115$ \\
\hline \multicolumn{9}{|l|}{ Urbanicity } \\
\hline Urban & $17 \cdot 7$ & $1 \cdot 00$ & Ref. & & $32 \cdot 5$ & $1 \cdot 00$ & Ref. & \\
\hline Rural & $20 \cdot 5$ & $1 \cdot 23$ & $0 \cdot 85,1 \cdot 78$ & 0.273 & $32 \cdot 8$ & $1 \cdot 70$ & $0.77,1.51$ & 0.678 \\
\hline \multicolumn{9}{|l|}{ Pregnancy characteristics } \\
\hline \multicolumn{9}{|l|}{ Health insurance } \\
\hline No & $23 \cdot 7$ & $1 \cdot 00$ & & & $26 \cdot 6$ & 1.00 & & \\
\hline Yes & $15 \cdot 8$ & 0.69 & $0.48,0.98$ & 0.040 & $36 \cdot 0$ & $1 \cdot 40$ & $0.99,1.96$ & 0.055 \\
\hline \multicolumn{9}{|l|}{ Prenatal care during pregnancy } \\
\hline No & $19 \cdot 9$ & $1 \cdot 00$ & Ref. & & $21 \cdot 2$ & $1 \cdot 00$ & Ref. & \\
\hline Yes & $18 \cdot 1$ & $1 \cdot 18$ & $0 \cdot 81,1 \cdot 71$ & 0.403 & $36 \cdot 5$ & $2 \cdot 22$ & $1 \cdot 52,3 \cdot 26$ & $<0.001$ \\
\hline \multicolumn{9}{|c|}{ 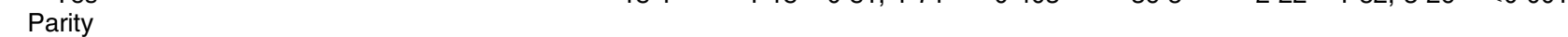 } \\
\hline Nulliparous & $26 \cdot 2$ & $1 \cdot 00$ & Ref. & & $22 \cdot 6$ & $1 \cdot 00$ & Ref. & \\
\hline Multiparous & $13 \cdot 9$ & 0.57 & $0 \cdot 41,0 \cdot 80$ & $<0.001$ & 38.9 & $1 \cdot 86$ & $1 \cdot 33,2 \cdot 59$ & $<0.001$ \\
\hline \multicolumn{9}{|l|}{ Trimester of pregnancy } \\
\hline $1 \mathrm{st}$ & $20 \cdot 6$ & 1.00 & Ref. & & $23 \cdot 7$ & $1 \cdot 00$ & Ref. & \\
\hline 2nd & $18 \cdot 4$ & $1 \cdot 00$ & $0.66,1.53$ & 0.993 & $32 \cdot 4$ & 1.54 & $1 \cdot 01,2 \cdot 34$ & 0.045 \\
\hline 3rd & $16 \cdot 5$ & $1 \cdot 07$ & $0 \cdot 68,1 \cdot 69$ & $0 \cdot 770$ & $42 \cdot 3$ & $2 \cdot 40$ & $1.57,3.67$ & $<0.001$ \\
\hline
\end{tabular}

POR, prevalence odds ratio; Ref., referent category.

leading to overweight and obesity ${ }^{(49)}$. Future studies assessing physical activity patterns and food consumption among pregnant women will help us to discern the differences in nutritional transition observed among pregnant Colombian women.

It is concerning that the prevalence of underweight is higher within the poorest and youngest population. In fact, $53 \%$ of adolescents were in the lowest WI quintile. In addition, about one out of five adolescents in the lowest WI quintile were underweight, compared with one out of seven adolescents in the highest WI quintile. This finding illustrates that the strong association between poverty and undernutrition persists in Colombia. Consistent with other developing countries, in Colombia poverty is one of the main factors associated with maternal undernutrition ${ }^{(44,52)}$. In Colombia, despite public and private efforts, the tendency towards teenage pregnancy accompanied by low gestational BMI has not changed and the proportion of pregnant adolescents has even increased, from $13 \%$ in 1990 to $22 \%$ in $2005^{(29)}$. It is also important to underscore that our analysis showed that $22.5 \%$ of the adolescents in our sample have already had at least one pregnancy. Undernutrition and multiple pregnancies could both increase the probability of giving birth to low-birthweight infants, thus creating an intergenerational effect on nutritional status and a transgenerational cycle of undernutrition and poverty ${ }^{(6,52)}$.

In addition, in the present study undernutrition was also reflected in the measurements of $\mathrm{Hb}$ and $\mathrm{SF}$ which showed that $44.7 \%$ of the women had anaemia. These estimates, however, did not differ between adolescents and pregnant women. This significant nutritional deficiency is consistent with the prevalence of anaemia during pregnancy in non-industrialized countries ${ }^{(11,53)}$ and reflects the enduring problem of nutritional deficiencies in Colombia. Programmes of supplementation with multiple micronutrients during pregnancy may be a reasonable public health strategy.

In contrast, we found that overweight and obesity were more prevalent among adult women. These prevalences are within the lower bound of overweight and obesity prevalences reported by the WHO in other Latin American countries (Bolivia: 49.7\%; Brazil: 43.0\%; Chile: $57 \cdot 7 \%$; Dominican Republic: $38 \cdot 3 \%$; Peru: $43 \cdot 4 \%)^{(34)}$. We also 
Table 4 Multivariate associations between nutritional status and sociodemographic and pregnancy characteristics among pregnant women in Colombia, Demographic and Health Survey (ENSIN) and National Nutritional Survey (ENDS), 2005

\begin{tabular}{|c|c|c|c|c|c|c|}
\hline \multirow[b]{2}{*}{ Variable } & \multicolumn{3}{|c|}{ Underweight $v$. normal weight } & \multicolumn{3}{|c|}{ Overweight $v$. normal weight } \\
\hline & POR & $95 \% \mathrm{Cl}$ & $P$ value & POR & $95 \% \mathrm{Cl}$ & $P$ value \\
\hline \multicolumn{7}{|l|}{ Sociodemographic characteristics } \\
\hline \multicolumn{7}{|l|}{ Age } \\
\hline Adolescence, 13-19 years & $1 \cdot 76$ & $1 \cdot 14,2 \cdot 73$ & 0.010 & 0.73 & $0 \cdot 47,1 \cdot 12$ & $0 \cdot 138$ \\
\hline Adult, $19-49$ years & 1.00 & Ref. & & $1 \cdot 00$ & Ref. & \\
\hline \multicolumn{7}{|l|}{ Education } \\
\hline No formal education or elementary school & $1 \cdot 00$ & Ref. & & $1 \cdot 00$ & Ref. & \\
\hline High school or higher education & $1 \cdot 48$ & $0 \cdot 99,2 \cdot 19$ & 0.053 & 0.82 & $0.58,1 \cdot 16$ & $0 \cdot 267$ \\
\hline \multicolumn{7}{|l|}{ Wealth index } \\
\hline 1 st and 2 nd quintiles & $1 \cdot 00$ & Ref. & & $1 \cdot 00$ & Ref. & \\
\hline 3rd quintile & 0.62 & $0.40,0.97$ & 0.350 & 0.97 & $0 \cdot 64,1 \cdot 50$ & 0.908 \\
\hline 4th and 5th quintiles & 0.56 & $0.34,0.91$ & 0.020 & $1 \cdot 13$ & $0 \cdot 70,1 \cdot 80$ & 0.621 \\
\hline \multicolumn{7}{|l|}{ Family structure } \\
\hline Single person or nuclear family & $1 \cdot 00$ & Ref. & & $1 \cdot 00$ & Ref. & \\
\hline Extended family & $1 \cdot 27$ & $0 \cdot 89,1 \cdot 81$ & $0 \cdot 189$ & 0.63 & $0.50,0.95$ & 0.025 \\
\hline \multicolumn{7}{|l|}{ Marital status } \\
\hline Single & $1 \cdot 00$ & Ref. & & $1 \cdot 00$ & Ref. & \\
\hline Married or member of an unmarried couple & $1 \cdot 17$ & $0.77,1.79$ & 0.461 & 0.93 & $0.64,1.35$ & 0.696 \\
\hline \multicolumn{7}{|l|}{ Urbanicity } \\
\hline Urban & 1.00 & & & $1 \cdot 00$ & & \\
\hline Rural & $1 \cdot 03$ & $0.67,1.57$ & 0.903 & $1 \cdot 08$ & $0 \cdot 72,1 \cdot 61$ & 0.725 \\
\hline \multicolumn{7}{|l|}{ Pregnancy characteristics } \\
\hline \multicolumn{7}{|l|}{ Health insurance status } \\
\hline None & $1 \cdot 00$ & Ref. & & $1 \cdot 00$ & Ref. & \\
\hline Yes & 0.69 & $0.46,1.04$ & 0.077 & $1 \cdot 15$ & $0.81,1 \cdot 62$ & 0.435 \\
\hline \multicolumn{7}{|l|}{ Prenatal care during pregnancy } \\
\hline No & $1 \cdot 00$ & Ref. & & $1 \cdot 00$ & Ref. & \\
\hline Yes & $1 \cdot 44$ & $0.91,2 \cdot 28$ & $0 \cdot 117$ & $2 \cdot 17$ & $1 \cdot 48,3.09$ & $<0.001$ \\
\hline \multicolumn{7}{|l|}{ Parity } \\
\hline Nulliparous & 1.00 & Ref. & & 1.00 & Ref. & \\
\hline Multiparous & 0.72 & $0 \cdot 47,1 \cdot 12$ & $0 \cdot 147$ & $2 \cdot 10$ & $1 \cdot 43,3 \cdot 15$ & $<0.001$ \\
\hline
\end{tabular}

POR, prevalence odds ratio; Ref., referent category.

found that multiparous females were more likely to be overweight. Weight increases gradually throughout adult life, and some studies have shown that excessive gestational weight gain is associated with postpartum weight retention and failure to lose pregnancy-related weight, both important predictors of obesity in midlife ${ }^{(37)}$. Overweight was also associated with living in extended families, which could be a reflection of food redistribution within families and should be evaluated in future studies.

The double burden of undernutrition among adolescents and overweight among women indicates the need to design and implement health and educational policies that promote healthy diets and physical activity during pregnancy. Therefore, it is important to emphasize the need for direct interventions to prevent excess or low gestational weight, to promote and maintain adequate pre-pregnancy healthy weight and to guarantee an adequate nutritional status during pregnancy in order to break the intergenerational transmission of unwanted health outcomes ${ }^{(24,54)}$.

In this context, we underscore the potential impact and relevance of nutritional programmes within the Colombian National Policy on Sexual and Reproductive Health, and the National Food and Nutritional Plan, which address malnutrition problems. In the private sector, widespread national programmes that include family planning and prenatal care health services offered by Profamilia could be determinant in preventing malnutrition outcomes in the pregnant population. In the public sector, the Colombian Institute for Family Welfare has maternal and child health and nutritional programmes, including day-care centres, nutritional programmes for pregnant and lactating women, and infant growth and development monitoring ${ }^{(28,55)}$. Unfortunately, despite indications that overweight has increased, even exceeding underweight among women over the last decades, public health policies and programmes targeting pregnant women to date have continued to focus mainly on reducing undernutrition $^{(33,56)}$.

As our research design was intended primarily to generate hypotheses, our findings should be interpreted with the following limitations. The study addressed neither pre-pregnancy weight nor weight gain during pregnancy, because of the cross-sectional design with only one anthropometric measurement. Nutritional status was evaluated using BMI based on weight and height measurements and the Atalah algorithm. However, this algorithm is being recommended for national surveys in Latin America ${ }^{(32)}$. Additionally, we did not assess food intake. We also found that prenatal care was positively associated with 
gestational overweight, which could be due to the cohort effect given the cross-sectional design of the study or the fact that our variable only reflected attending at least one prenatal care appointment. Therefore, longitudinal research is needed on whether our finding is related to health-care access and quality.

Despite the limitations of the study, it provides new evidence of the double burden as an illustration of the epidemiological and nutritional transition among pregnant women from a middle-income country in Latin America. Although preventing low gestational weight is an urgent matter, preventing overweight during pregnancy is also crucial because of the complications of obesity during pregnancy ${ }^{(6,22,26)}$. Public health policies and efforts towards preventing underweight in pregnant adolescents and overweight in pregnant adult women should be reinforced.

\section{Acknowledgements}

The Demographic and Health Survey of Colombia 2005 was funded by the US Agency for International Development (USAID), the United Nations Population Fund (UNFPA), the Colombian Institute of Family Welfare (ICBF) and Colombia's Ministry of Social Protection. O.L.S., A.C.O., P.L.P. and A.R. received funding from the Epidemiology Group at Universidad de los Andes \#1808. The authors declare that they have no conflict of interests. All authors were involved with data interpretation, critical revisions of the paper and provided approval for its publication.

\section{References}

1. Uauy R, Albala C \& Kain J (2001) Obesity trends in Latin America: transiting from under- to overweight. J Nutr 131, issue 3, 893S-899S.

2. Swinburn BA, Sacks G, Hall KD et al. (2011) The global obesity pandemic: shaped by global drivers and local environments. Lancet 378, 804-814.

3. Doak CM, Adair LS, Bentley M et al. (2005) The dual burden household and the nutrition transition paradox. Int J Obes (Lond) 29, 129-136.

4. Mendez MA, Monteiro CA \& Popkin BM (2005) Overweight exceeds underweight among women in most developing countries. Am J Clin Nutr 81, 714-721.

5. Abenhaim HA, Kinch RA, Morin L et al. (2007) Effect of prepregnancy body mass index categories on obstetrical and neonatal outcomes. Arch Gynecol Obstet 275, 39-43.

6. Black RE, Allen LH, Bhutta ZA et al. (2008) Maternal and child undernutrition: global and regional exposures and health consequences. Lancet 371, 243-260.

7. Ramakrishnan U (2004) Nutrition and low birth weight: from research to practice. Am J Clin Nutr 79, 17-21.

8. Davies AA, Smith GD, May MT et al. (2006) Association between birth weight and blood pressure is robust, amplifies with age, and may be underestimated. Hypertension 48, 431-436.

9. Haider BA, Yakoob MY \& Bhutta ZA (2011) Effect of multiple micronutrient supplementation during pregnancy on maternal and birth outcomes. BMC Public Health 11, Suppl. 3, S19.

10. Phillips DI, Barker DJ, Hales CN et al. (1994) Thinness at birth and insulin resistance in adult life. Diabetologia 37, 150-154.

11. World Health Organization/UNICEF/United Nations University (2001) Iron Deficiency Anaemia. Assessment, Prevention and Control. A Guide for Programme Managers. Geneva: WHO; available at http://www.who.int/nutrition/publications/en/ ida_assessment_prevention_control.pdf

12. Lee AI \& Okam MM (2011) Anemia in pregnancy. Hematol Oncol Clin North Am 25, 241-259.

13. Yogev Y \& Catalano PM (2009) Pregnancy and obesity. Obstet Gynecol Clin North Am 36, 285-300.

14. Linne Y (2004) Effects of obesity on women's reproduction and complications during pregnancy. Obes Rev 5, 137-143.

15. Martorell R, Khan LK, Hughes ML et al. (2000) Obesity in women from developing countries. Eur J Clin Nutr $\mathbf{5 4}$, $247-252$.

16. Van EP (2011) Obesity in pregnancy. S D Med Spec No: 46-50.

17. Ehrenberg HM, Dierker L, Milluzzi C et al. (2002) Prevalence of maternal obesity in an urban center. Am J Obstet Gynecol 187, 1189-1193.

18. LaCoursiere DY, Bloebaum L, Duncan JD et al. (2005) Population-based trends and correlates of maternal overweight and obesity, Utah 1991-2001. Am J Obstet Gynecol 192, 832-839.

19. Santos IS, Barros AJ, Matijasevich A et al. (2008) Mothers and their pregnancies: a comparison of three populationbased cohorts in Southern Brazil. Cad Saude Publica 24, Suppl. 3, S381-S389.

20. Rayis DA, Abbaker AO, Salih Y et al. (2010) Epidemiology of underweight and overweight-obesity among term pregnant Sudanese women. BMC Res Notes 3, 327.

21. Villamor E, Msamanga G, Urassa W et al. (2006) Trends in obesity, underweight, and wasting among women attending prenatal clinics in urban Tanzania, 1995-2004. Am J Clin Nutr 83, 1387-1394.

22. Leddy MA, Power ML \& Schulkin J (2008) The impact of maternal obesity on maternal and fetal health. Rev Obstet Gynecol 1, 170-178.

23. Siega-Riz AM \& King JC (2009) Position of the American Dietetic Association and American Society for Nutrition: obesity, reproduction, and pregnancy outcomes. J Am Diet Assoc 109, 918-927.

24. Reece EA (2008) Perspectives on obesity, pregnancy and birth outcomes in the United States: the scope of the problem. Am J Obstet Gynecol 198, 23-27.

25. Anderson JL, Waller DK, Canfield MA et al. (2005) Maternal obesity, gestational diabetes, and central nervous system birth defects. Epidemiology 16, 87-92.

26. Poston L, Harthoorn LF \& Van Der Beek EM (2011) Obesity in pregnancy: implications for the mother and lifelong health of the child. A consensus statement. Pediatr Res 69, 175-180.

27. Seligman LC, Duncan BB, Branchtein L et al. (2006) Obesity and gestational weight gain: cesarean delivery and labor complications. Rev Saude Publica 40, 457-465.

28. Profamilia (2005) Encuesta Nacional en Demografía y Salud 2005 (ENDS 2005) - Resultados Generales. http://www. profamilia.org.co/encuestas/01encuestas/2005resultados_ generales.htm (accessed December 2011).

29. Departamento Administrativo Nacional de Estadística (2005) Censo General, Colombia 2005. Bogotá: DANE; available at http://www.dane.gov.co/censo/

30. Banco Mundial (2009) Reseña sobre Colombia. http:// web.worldbank.org/WBSITE/EXTERNAL/BANCOMUNDIAL/ EXTSPPAISES/LACINSPANISHEXT/COLUMBIAINSPANISHEXTN/ 0,,contentMDK:20235281 pagePK:1497618 piPK:217854 theSitePK:455460,00.html (accessed December 2011). 
31. Demographic and Health Survey (2002) DHS and World Bank Use Wealth Index to Measure Socioeconomic Status. $D H S^{+}$ Dimensions 4, issue 2; available at http://www.measuredhs. $\mathrm{com} / \mathrm{pubs} / \mathrm{pdf} / \mathrm{NL} 42 / \mathrm{Vol} 4 \mathrm{no}$.pdf

32. Atalah E, Castillo C, Castro R et al. (1997) Proposal of a new standard for the nutritional assessment of pregnant women. Rev Med Chil 125, 1429-1436.

33. Atalah E \& Castro R (2004) Maternal obesity and reproductive risk. Rev Med Chil 132, 923-930.

34. World Health Organization (2006) Global Databases on Body Mass Index. WHO: Geneva; available at http:// apps.who.int/bmi/index.jsp

35. Billewicz W \& Thomson A (1957) Clinical significance of weight trends during pregnancy. Br Med J 1, 243-247.

36. Gale CR, Javaid MK, Robinson SM et al. (2007) Maternal size in pregnancy and body composition in children. J Clin Endocrinol Metab 92, 3904-3911.

37. Gore SA, Brown DM \& West DS (2003) The role of postpartum weight retention in obesity among women: a review of the evidence. Ann Behav Med 26, 149-159.

38. Leddy MA, Power ML \& Schulkin J (2008) The impact of maternal obesity on maternal and fetal health. Rev Obstet Gynecol 1, 170-178.

39. Grandi C, Luchtenberg G \& Sola H (2007) Nutrition assessment during pregnancy. A new weight chart. Medicina (B Aires) 67, 677-684.

40. Rached-Paoli I, Henriquez-Perez G \& Azuaje-Sanchez A (2005) Effectiveness of body mass index in the nutritional diagnosis of pregnant women. Arch Latinoam Nutr 55, 42-46.

41. Atalah E, Rosales E, Barja I et al. (1980) Maternal nutrition and fetal growth: Chilean perspectives. Rev Med Chil $\mathbf{1 0 8}$, 351-357.

42. Rached-Paoli I \& Henriquez-Perez G (2010) Effectiveness of the body mass index in the nutritional diagnosis of pregnant adolescents. Arch Latinoam Nutr 60, 141-147.

43. Mardones F \& Rosso P (1997) Design of a weight gain chart for pregnant women. Rev Med Chil 125, 1437-1448.
44. Benjumea MV (2007) Diagnostic accuracy of five gestational references to predict insufficient birth weight. Biomedica 27, 42-55.

45. World Health Organization (2007) Adolescent Pregnancy. Unmet Needs and Undone Deeds. A Review of the Literature and Programmes. WHO: Geneva.

46. International Anemia Consultative Group (2002) Adjusting Hemoglobin Values in Program Surveys. Washington, DC: INACG Secretariat; available at http://pdf.usaid.gov/ pdf_docs/PNACQ927.pdf

47. Ciok J \& Leibschang J (1999) The report of UNICEF/WHO Joint Consultation on iron deficiency anemia, Geneva, February 3-5, 1999. Ginekol Pol 70, 573-577.

48. Sullivan KM, Mei Z, Grummer-Strawn L et al. (2008) Haemoglobin adjustments to define anaemia. Trop Med Int Health 13, 1267-1271.

49. Popkin BM \& Gordon-Larsen P (2004) The nutrition transition: worldwide obesity dynamics and their determinants. Int J Obes Relat Metab Disord 28, Suppl. 3, S2-S9.

50. Barria RM \& Amigo H (2006) Nutrition transition: a review of Latin American profile. Arch Latinoam Nutr 56, 3-11.

51. Ha do TP, Feskens EJ, Deurenberg P et al. (2011) Nationwide shifts in the double burden of overweight and underweight in Vietnamese adults in 2000 and 2005: two national nutrition surveys. BMC Public Health 11, 62.

52. Muller O \& Krawinkel M (2005) Malnutrition and health in developing countries. CMAJ 173, 279-286.

53. Stoltzfus RJ (2003) Iron deficiency: global prevalence and consequences. Food Nutr Bull 24, 4 Suppl., S99-S103.

54. Oken E (2009) Maternal and child obesity: the causal link. Obstet Gynecol Clin North Am 36, 361-377.

55. Siega-Riz AM, Siega-Riz AM \& Laraia B (2006) The implications of maternal overweight and obesity on the course of pregnancy and birth outcomes. Matern Child Health J 10, 5 Suppl., S153-S156.

56. Atalah E, Castillo C, Gomez C et al. (1995) Malnutrition of the pregnant woman: an overestimated problem? Rev Med Chil 123, 1531-1538. 